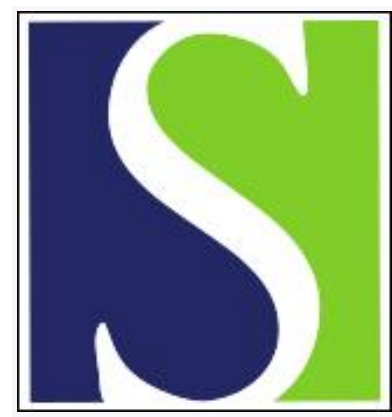

Scand J Work Environ Health 2018;44(1):80-87

https://doi.org/10.5271/sjweh.3673

Published online: 26 Sep 2017, Issue date: 01 Jan 2018

Personal light-at-night exposures and components of variability in two common shift work industries: uses and implications for future research

by Hall AL, Davies HW, Koehoorn M

This study assessed personal light-at-night exposure levels and variance components for shift workers, using multiple exposure indices and metrics. Findings suggest that high-level grouping schemes for light-at-night exposure could provide a simple yet effective way of describing individual light-at-night exposure, and multiple light-at-night exposure metrics may be useful in epidemiological studies (depending upon the conceptual nature of the research question).

Affiliation: School of Population and Public Health, University of British Columbia, 2206 East Mall, Vancouver, V6T1Z3, Canada. amyhall@mail.ubc.ca

Refers to the following texts of the Journal: 1995;21(1):43-50 2010;36(2):81-84 2013;39(5):431-447

Key terms: circadian disruption; exposure; exposure assessment; exposure metric; LAN; light at night; light exposure; light-at-night; light-at-night exposure; night work ; research; shift work; shift worker; variability

This article in PubMed: www.ncbi.nlm.nih.gov/pubmed/28951937

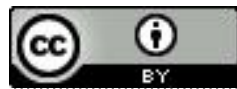




\title{
Personal light-at-night exposures and components of variability in two common shift work industries: uses and implications for future research
}

\author{
by Amy L Hall, PhD, ${ }^{1,2}$ Hugh W Davies, PhD, ClH, ${ }^{1}$ Mieke Koehoorn, PhD ${ }^{1}$
}

\begin{abstract}
Hall AL, Davies HW, Koehoorn M. Personal light-at-night exposures and components of variability in two common shift work industries: uses and implications for future research. Scand J Work Environ Health. 2018;44(1):80-87. doi:10.5271/sjweh.3673
\end{abstract}

Objectives Shift workers' increased risk of various adverse health outcomes has been linked to light-at-night
(LAN) exposure, but few studies have measured LAN exposure in workplaces. To inform future research meth-
ods, this study aimed to (i) measure shift workers' exposures to LAN across industries, occupations, and work
environments and (ii) assess components of variance across different exposure groupings and metrics.

Methods Between October 2015 and March 2016, 152 personal full-shift measurements were collected from 102 night shift workers in emergency services (paramedics, dispatchers) and healthcare (nurses, care aides, security guards, unit clerks, and laboratory, pharmacy, and respiratory therapy staff) industries in the province of British Columbia, Canada. Descriptive and variance component analyses were conducted for the 23:00-05:00 period to characterize exposures using multiple metrics of potential biological relevance (median lux, 90th percentile lux, sum of minutes $\geq 30$ lux, and sum of minutes $\geq 100$ lux).

Results Average exposure levels were highest in the healthcare industry. By occupation, laboratory workers and care aides displayed the highest and emergency dispatch officers displayed the lowest levels for all LAN exposure metrics. Between-group variance was large relative to within-group variance for all exposure groupings and metrics, and increased as grouping specificity increased (moving from industry to occupation).

Conclusions Results from this study suggest that high-level grouping schemes may provide a simple yet effective way of characterizing individual LAN exposures in epidemiological studies of shift work. Ongoing measurement of LAN exposures and assessment of exposure variability is needed in future studies of shift workers as a means to increase sampling efficiency, reduce measurement error, and maximize researchers' ability to detect relationships where they exist.

Key terms circadian disruption; exposure assessment; exposure metric; LAN; light exposure; night work; shift worker.

The biological processes of humans operate on 24-hour (circadian) cycles that are synchronized primarily by natural periods of light and dark. In the modern world, artificial light confers a number of social and economic benefits. However, exposure to light during the biological night has been linked to a number of physiological disturbances that may negatively affect health $(1,2)$.

One population at increased risk of physiological disturbances arising from light-at-night (LAN) exposures is shift workers, particularly those who work evening, night, or early morning shifts. A number of epidemiological studies have shown that shift workers are at increased risk of acute and chronic health effects $(2,3)$, which are directly or indirectly related to exposure to LAN (1).

The physiological consequences of light exposure during the biological night are well established in animal studies (2) but less so for humans, due partly to a lack of quantitative exposure data collected in observational settings (4). This speaks to a common limitation in epidemiological studies of shift work, in that characteristics relevant to health risks are often not sufficiently captured and described in the process of exposure assessment $(5,6)$. For example, the International Agency for

1 School of Population and Public Health, University of British Columbia, Vancouver, Canada.

2 International Agency for Research on Cancer, Lyon, France.

Correspondence to: Amy L Hall, School of Population and Public Health, University of British Columbia, 2206 East Mall, Vancouver, V6T1Z3, Canada. [E-mail: amyhall@mail.ubc.ca] 
Research on Cancer recently classified shift work that involves circadian disruption as "probably carcinogenic to humans" (Group 2A), based on limited evidence in humans working night shifts and sufficient evidence in animal studies assessing the carcinogenicity of light exposure during the biological night (2). The working group responsible for this classification noted "an important limitation of the available epidemiological studies is that there have not been clear and uniform definitions of 'shift work' used", and recommended LAN as a domain for capture in future studies (5). Since epidemiological studies evaluate health risks by comparing outcomes across groups of exposed versus unexposed persons, it is indeed essential to collect and utilize LAN exposure measures that are precise, accurate, and biologically relevant in order to avoid biased associations in exposure-response relationships (7).

\section{Rationale and objectives}

Quantitative measurements are needed to investigate relationships between LAN exposures and health outcomes among shift workers. For example, such measurements can be used to select samples with maximal exposure variability, thereby increasing sampling efficiency by minimizing the number of participants to achieve a sufficient level of study power (8). Exposure data can also be used to inform appropriate grouping strategies for assigning exposure estimates, which increase contrast and enhance the ability to detect exposure-response relationships (9). Furthermore, empirical data that describe LAN exposures can be used to identify groups of shift workers at risk of negative health outcomes for targeted research and workplace prevention efforts, such as those at greatest risk of fatigue (ie, where LAN exposures are consistently low) or melatonin suppression (ie, where LAN exposures are consistently high).

Workplace exposures vary across a number of factors, such as work content, tasks performed, production characteristics, and time (10). Foundational information on exposure levels and variability provides an important scientific basis for the planning, analysis, and interpretation of epidemiological studies $(7,11)$, however there has been limited measurement of LAN exposure in "real-life" environments to date (12), and the variability of such exposures has not been examined. To inform exposure assessment methods in future epidemiological research, this study aimed to answer the following questions in a sample of healthcare and emergency services workers: (i) What are the LAN exposures of shift workers, and do these exposures vary by industry and occupation? (ii) What are the components of variance for LAN exposures (within-worker, between-worker, and between-group) across different exposure groupings and metrics?

\section{Methods}

Full-shift data on LAN exposures were collected from shift workers in emergency services and healthcare industries employed by the Provincial Health Services Authority, within the province of British Columbia, Canada. These industry sectors were chosen since they employ a substantial proportion of shift workers in the province and were expected to represent a range of lighting conditions.

\section{Exposure metrics}

In situations where the most biologically relevant indicator of exposure is unknown, and where multiple exposure indices may be relevant, the assessment of multiple metrics can be useful (13). Although there are currently no standard health-based exposure metrics used in epidemiological studies of LAN (14), some exposure thresholds have been proposed for biological indicators of acute alertness and melatonin suppression. One study examining the dose-response relationship between photopic illuminance (described in units of lux, a measure of light intensity as perceived by the human eye) and subjective alertness found that room light of $\sim 100$ lux elicited half of the maximum alerting response (that occurred at bright light of 9100 lux) (15). Increasing light levels measured in terms of photopic illuminance has also been found to suppress melatonin secretion in humans (16); exposure to 30 lux at the cornea from "white" light sources for 30 minutes has been proposed as a working threshold for acute nocturnal suppression (17).

This study examined four metrics of photopic illuminance between 23:00-05:00 hours. These were: median lux, to characterize central tendencies; 90th percentile lux, to characterize peak exposures; sum of minutes $\geq 30$ lux, to characterize duration of exposure that may suppress melatonin production; and sum of minutes $\geq 100$ lux, to characterize duration of exposure that may elicit half of the maximal alerting response.

\section{Recruitment and data collection}

Sampling was conducted between October 2015 and April 2016 in ambulance stations, emergency dispatch offices, and a large acute care hospital. Participants were emergency health services workers (paramedics and dispatch officers) and hospital workers (nurses, care aides, security guards, unit clerks, and medical laboratory, pharmacy and respiratory therapy staff) who were working one or more overnight shifts.

Stratified sampling was conducted to capture workers in a range of occupations and work environments. 
To inform future workplace exposure sampling methods and to permit calculations of exposure variance between and within workers, the recruitment target was 100 shift workers with repeated measurements for up to 2 shifts per worker. At minimum, 5 shift workers were recruited within each worksite.

Personal measurements of photopic illuminance were collected using the Daysimeter (18), a small light monitoring device that has been validated (19) and used in prior studies to examine the impacts of light exposures on health (20-22). This device continuously records optical radiation from ambient light sources using an integrated circuit light sensor array $(19,23)$.

The study coordinator was present on site at the beginning of each participant's first work shift to deliver his or her Daysimeter and administer a short in-person training session. Each participant was instructed to wear his or her monitor on the upper chest, suspended from a lanyard with the light sensor facing outward, for the entire night shift. Optical radiation measurements were logged at a rate of one measurement per minute and downloaded to a computer at the end of each shift for processing into units of photopic illuminance, in lux.

\section{Statistical analysis}

All study participants worked overnight shifts that included 23:00-05:00 hours, except security guards who started their shifts at midnight. Since no major differences in exposure were noted by hour for security guards, measurements from each security guard's 00:0001:00 period were extrapolated to the 23:00-00:00 period. This was done to retain security guards in the analytic sample, and to enable comparisons with other worker groups across the 6-hour exposure window.

Summary statistics for each exposure metric were calculated by industry and occupation. Distributions of median and sum of minutes $\geq 100$ lux exposure distributions were lognormal and therefore log-transformed prior to analyses. Distributions of $90^{\text {th }}$ percentile and sum of minutes $\geq 30$ lux exposure distributions were approximately normal and not transformed. Each exposure metric was grouped by industry (two groups), workplace (four groups), work site (nine groups) and occupation (ten groups), as presented in table 1. To identify the relative contribution of each variance component (within-worker, between-worker, and between-group) to total variance, a series of random effects (or "null") models was generated using PROC MIXED in SAS, version 9.4 (SAS Institute, Cary, NC, USA). The first model included only worker as a random effect (Model 1); four subsequent models examined each grouping: worker + industry (Model 2), worker + workplace (Model 3), worker + worksite (Model 4), and worker + occupation (Model 5).
Table 1. Summary of grouping schemes for shift workers' personal light-at-night exposures (N participants, $\mathrm{N}$ samples a) [LDR=labor and delivery; NICU=neonatal intensive care unit; Lab=medical laboratory, Circ=Circulating]

\begin{tabular}{|c|c|c|c|}
\hline Industry & Workplace & Worksite & Occupation \\
\hline $\begin{array}{l}\text { Emergency } \\
\text { services } \\
(33,47)\end{array}$ & $\begin{array}{l}\text { Call centre } \\
(19,30) \\
\text { Various }{ }^{\mathrm{b}} \\
(14,17)\end{array}$ & $\begin{array}{l}\text { Call centre - Vancouver } \\
(14,22) \\
\text { Call centre - Victoria }(5,8) \\
\text { Various }^{\mathrm{b}} \text { - Surrey }(9,11) \\
\text { Various }^{\mathrm{b}} \text { - Delta }(5,6)\end{array}$ & $\begin{array}{l}\text { Dispatch officer } \\
(19,30) \\
\text { Paramedic }(14,17)\end{array}$ \\
\hline $\begin{array}{l}\text { Healthcare } \\
(69,105)\end{array}$ & $\begin{array}{l}\text { Hospital } \\
\text { unit }{ }^{c} \\
(58,84) \\
\text { Hospital } \\
\text { other }^{d} \\
(11,21)\end{array}$ & $\begin{array}{l}\text { Hospital unit - LDR } \\
(23,31) \\
\text { Hospital unit - NICU } \\
(27,34) \\
\text { Hospital unit - Ward }(12, \\
20) \\
\text { Hospital other - Lab }(5,10) \\
\text { Hospital other - Circ }(6,11)\end{array}$ & $\begin{array}{l}\text { Nurse }(38,56) \\
\text { Lab technologist } \\
(2,4) \\
\text { Lab assistant }(3,6) \\
\text { Care aide }(11,17) \\
\text { Security guard } \\
(5,9) \\
\text { Unit clerk }(4,7) \\
\text { Pharmacist }(4,4) \\
\text { Respiratory } \\
\text { therapist }(2,2)\end{array}$ \\
\hline 2 groups & 4 groups & 9 groups & 10 groups \\
\hline
\end{tabular}

\section{Results}

A total of 155 personal full-shift LAN measurements were obtained from 104 participants over 45 nights. Three measurements were excluded due to technical errors $(\mathrm{N}=1)$ or compliance reasons $(\mathrm{N}=2)$, giving a final analytic sample of 102 participants (k) and 152 measurements (n). Repeated measurements on the same participant ( $\mathrm{N}=50$, or $49 \%)$ were performed on average 11 days after the initial shift (range 1-42 days).

Average LAN exposures for the 23:00-05:00 period over all measurement shifts are presented in table 2 . Average exposure levels were highest in the healthcare industry. By occupation, laboratory workers (technologists and assistants) and care aides displayed the highest and emergency dispatch officers displayed the lowest levels for all LAN exposure metrics.

Within-worker, between-worker, and between-group variances for each grouping scheme across all exposure metrics are presented in table 3. Between-group variance was large for all exposure metrics and increased as grouping specificity increased (moving from industry to occupation). Within-worker variance and betweenworker variance was small relative to between-group variance for all exposure metrics and groupings. 
Table 2. Personal light-at-night exposure averages (assessed from 23:00-05:00 hours).

\begin{tabular}{|c|c|c|c|c|c|c|}
\hline & $\mathrm{k}^{\mathrm{a}}$ & $\mathrm{N}^{b}$ & $\begin{array}{c}\text { Median } \\
\quad(\text { lux })\end{array}$ & $\begin{array}{l}90^{\text {th }} \\
\text { percen- } \\
\text { tile } \\
\text { (lux) }\end{array}$ & $\begin{array}{l}\text { Sum of } \\
\text { minutes } \\
\geq 30 \text { lux }\end{array}$ & $\begin{array}{c}\text { Sum of } \\
\text { minutes } \\
\geq 100 \\
\text { lux }\end{array}$ \\
\hline Participants (all) & 102 & 152 & 23 & 73 & 122 & 28 \\
\hline Healthcare (all) & 69 & 105 & 29 & 88 & 151 & 36 \\
\hline Nurse & 38 & 56 & 22 & 77 & 120 & 30 \\
\hline Care aide & 11 & 17 & 36 & 143 & 197 & 58 \\
\hline Security guard & 5 & 9 & 28 & 66 & 153 & 17 \\
\hline Unit clerk & 4 & 7 & 19 & 43 & 107 & 3 \\
\hline Laboratory assistant & 3 & 6 & 67 & 121 & 262 & 83 \\
\hline Laboratory technologist & 2 & 4 & 60 & 112 & 292 & 69 \\
\hline Pharmacist & 4 & 4 & 30 & 97 & 178 & 40 \\
\hline Respiratory therapist & 2 & 2 & 14 & 38 & 94 & 6 \\
\hline Emergency services (all) & 33 & 47 & 11 & 40 & 59 & 11 \\
\hline Dispatch officer & 19 & 30 & 8 & 12 & 15 & 1 \\
\hline Paramedic & 14 & 17 & 18 & 88 & 137 & 28 \\
\hline
\end{tabular}

${ }^{a}$ Workers per group.

${ }^{\mathrm{b}}$ Workers per group $\times$ measurements shifts per workers $=$ total worker shifts.

\section{Discussion}

This study measured LAN exposures and assessed components of variability in a sample of emergency services and healthcare shift workers in an effort to inform exposure assessment methods in epidemiological studies.

Average LAN exposures between 23:00-05:00 hours varied across industries and occupation. In the healthcare industry, the highest average levels for all exposure metrics were observed among laboratory workers (technologists and assistants) and care aides while the lowest average levels for all exposure metrics were observed among respiratory therapists and unit clerks. These results are consistent with recommended light levels for visual tasks in laboratory work (200-2000 lux), as well as recommended light levels in and around nursing stations (20 lux in nighttime corridors up to 500 lux in general areas) (24) where unit clerks and respiratory therapists spent much of their time (note: photopic illuminance measured at the cornea is substantially lower than photopic illuminance measured on the horizontal plane, eg, as reported in lighting guidelines). In the emergency services industry, dispatch officers working in call centers displayed the lowest average lighting exposures across all LAN metrics. This finding was not unexpected, since study participants in these work environments expressed a preference for low lighting levels during their overnight shifts. Night time lighting levels may differ in other office settings given the range of recommended lighting levels for such environments (24).

The measurements obtained in this study can be compared with other studies that have examined LAN exposures in workplaces. Median light levels of 38 lux between 00:00-05:00 hours were found in one Spanish
Table 3. Proportions of variance in four light-at-night exposure metrics across grouping schemes, accounted for by betweengroup, between-worker, and within-worker components ( $N=152$ observations) (assessed from 23:00-05:00 hours).

\begin{tabular}{|c|c|c|c|c|}
\hline & $\begin{array}{l}\text { Median } \\
(\text { lux })^{\text {a }}\end{array}$ & $\begin{array}{l}90^{\text {th }} \\
\text { percen- } \\
\text { tile } \\
\text { (lux) }\end{array}$ & $\begin{array}{l}\text { Sum of } \\
\text { minutes } \\
\geq 30 \text { lux }\end{array}$ & $\begin{array}{c}\text { Sum of } \\
\text { minutes } \\
\geq 100 \\
\text { lux }^{a}\end{array}$ \\
\hline & $\%$ & $\%$ & $\%$ & $\%$ \\
\hline \multicolumn{5}{|l|}{$\begin{array}{l}\text { Model 1: No grouping - worker } \\
\text { random effect only }\end{array}$} \\
\hline Between-worker variance & 97.3 & 90.4 & 92.7 & 93.1 \\
\hline Within-worker variance & 3.7 & 10.6 & 8.3 & 7.9 \\
\hline \multicolumn{5}{|l|}{ Model 2: Industry (2 groups) } \\
\hline Between-industry variance & 91.4 & 62.8 & 64.1 & 62.7 \\
\hline Between-worker variance & 5.6 & 25.8 & 27.6 & 29.5 \\
\hline Within-worker variance & 3.0 & 11.4 & 8.4 & 7.8 \\
\hline \multicolumn{5}{|l|}{ Model 3: Workplace (4 groups) } \\
\hline Between-workplace variance & 93.2 & 70.7 & 78.9 & 75.3 \\
\hline Between-worker variance & 4.1 & 18.8 & 14.6 & 18.1 \\
\hline Within-worker variance & 2.7 & 10.5 & 6.5 & 6.6 \\
\hline \multicolumn{5}{|l|}{ Model 4: Worksite (9 groups) } \\
\hline Between-worksite variance & 93.6 & 71.7 & 79.9 & 76.5 \\
\hline Between-worker variance & 3.6 & 17.4 & 13.7 & 17.1 \\
\hline Within-worker variance & 2.8 & 10.8 & 6.4 & 6.4 \\
\hline \multicolumn{5}{|l|}{ Model 5: Occupation (10 groups) } \\
\hline Between-occupation variance & 94.6 & 80.1 & 85.8 & 81.5 \\
\hline Between-worker variance & 3.1 & 10.7 & 9.1 & 12.7 \\
\hline Within-worker variance & 2.3 & 9.2 & 5.1 & 5.9 \\
\hline
\end{tabular}

a Log-transformed.

study of workers from a variety of industries, including hospitals (25). In Canada, researchers reported a mean light intensity of 7.2 lux (SD 6.7) between 00:00-05:00 hours for nurses in one study (21) and a maximum of 37.2 lux for the same time period among nurses in a separate study (26). These results compare fairly well with the current study, where the average median exposure between 23:00-05:00 hours was 22 lux for nurses and 29 lux for hospital workers overall.

\section{Components of variance}

Grouped exposure assessment is common in occupational epidemiological studies since data on individual exposures are often missing (in the case of historical exposures) or can be impractical or costly to collect. While grouped exposure assessment can provide an efficient means of predicting individual exposures, the validity of this approach relies on the assumption that individuals within groups are similarly exposed (11). Since the choice of grouping scheme can have an important effect on the slope and standard error of exposure-response relationships (27), the magnitude of variance components (within-worker, between-worker, and between-group) should be investigated using individual-level measurements.

Within-worker exposure differences are primarily 
driven by temporal variability (7). This was examined in the current study by collecting repeated measurements from $49 \%$ of participants. Low within-worker variability (range 2.3-11.4\% of total variance) was observed for all LAN exposure metrics; differing from other occupational studies that have demonstrated high withinworker variability for exposures such as magnetic fields (28) and mercury (29). This is likely due to the relative stability of LAN, where exposures are less affected by specific work tasks or activities compared to other types of occupational exposures.

Between-worker differences may arise from differences in job characteristics (eg, work location, tasks) and personal characteristics (eg, sex, age, body size, techniques used to carry out tasks). As workers are consolidated into smaller classification groups with fewer subjects, between-worker variability typically decreases and between-group variability increases (30). The current study's LAN exposure variance components reflect this, with between-worker variance decreasing as classification groups become more specific (from large industry groupings to smaller occupation groupings). Between-group variance was lowest for industry (two groups, 33-69 workers per group) and highest for occupation (ten groups, 2-38 workers per group) for all exposure metrics.

Between-group differences describe variation between exposure groups that are established by the investigator (eg, occupation, workplace, industry) (31). In this study, the median exposure metric for photopic illuminance showed the greatest proportion of betweengroup relative to within-group variability for all exposure groupings, with up to $94.6 \%$ of variance explained by differences across occupations. Similar results were observed for the 90th percentile, sum of minutes $\geq 30$ lux, and sum of minutes $\geq 100$ lux exposure metrics, with between-group differences explaining 80.1\%, 85.8\%, and $81.5 \%$ of total variance, respectively.

\section{Implications for future research}

An explorative study can be very useful for gathering the information needed to optimize exposure assessment strategies and assign exposure indicators that reduce the potential for measurement error $(7,11)$. The high ratio of between- to within-group variance observed in this study shows promise for future sampling strategies and exposure categorization in epidemiological research focused on LAN. The high-level information required to develop such groupings (eg, occupation) is relatively easy to access and may prove to be a consistently efficient way of grouping LAN exposures to minimize exposure measurement error. The use of high-level groupings is also an important consideration regarding measurement burden, since night work is prevalent and individual-based assessments are not always practical due to financial or logistical constraints (9).

In most situations, optimal exposure assessment strategies require a balance between maximizing the number of individuals measured to account for between-person variability, and maximizing the number of measurements collected from each worker to account for within-worker (temporal) variability (7). Given that this is the first assessment of LAN exposure variability components, it will be interesting to compare these findings with variance components in future studies of other occupations, workplaces, industries, and regions. If within-worker (temporal) variability is consistently low, researchers may decide to re-direct study resources towards sampling a larger number of workers across different workplaces and lighting environments, rather than repeatedly sampling individual workers.

The importance of characterizing LAN exposure levels and variability was recently emphasized in a literature review focused on the quantitative measurement of LAN and melatonin levels to assess cancer risks in shift workers (14). The authors of this review posit that some of the contradictory results between studies concerning the relationship between LAN exposure and melatonin levels may be due to a lack of quantitative data describing LAN exposures, and inconsistent measurement techniques. Furthermore, they suggest that the lack of effects observed between LAN exposures and melatonin response in some studies may be explained by the participants' low LAN exposure levels (14). This supports the need for quantitative LAN exposure data and consideration of variance components, to select study samples that maximize exposure variability and reduce the potential for exposure misclassification and attenuated exposure-response relationships.

Quantitative data describing LAN exposures could also be used to construct job exposure matrices for use in estimating shift work related exposures in large epidemiological studies. There are a number of opportunities for refinement in this area, since to date most shift work job exposure matrices have focused on assessing the probability of exposure to night shift work rather than specific characteristics of shift work (such as LAN exposures) that may affect health (32). Quantitative measurements of LAN exposure could be used to develop exposure estimates that are less prone to exposure misclassification and bias versus subjectively defined measures (32), and to test the validity of subjective proxy measures (eg, self-reported exposures or expert assessment). Variance components estimated from quantitative measurements could also be applied to optimize the performance of a shift work job exposure matrix by identifying grouping variables (such as industry, job, or worksite) that most effectively 
discriminate homogenous groups to increase exposure contrast (33).

\section{Strengths and limitations}

In this study, the evaluation of LAN exposures in shift workers focused on the 23:00-05:00 hours timeframe. This was done to capture exposures during the period of natural darkness for humans and allow for comparisons between workers, many of whom had varying start/ end times to their night shifts. Other research has been conducted to examine 24-hour patterns of light exposure among shift workers $(20,22)$ since an individual's exposure to light throughout the 24-hour period can affect their circadian entrainment (and disruption) (34). However, the objective of this study was to provide baseline data on LAN exposures and exposure variability at work, using various exposure grouping schemes and metrics. This information serves a different purpose, such as to inform sampling strategies that maximize exposure contrast in occupational studies or to develop exposure indices that take LAN exposure variability into account (eg, assessing injury rates across shift workers employed in a variety of lighting environments).

The recruitment aim of this study was to capture measurements from a variety of occupations and work environments within two industries where shift work is common. Given the ubiquity of light, it is unlikely that this study's results were affected by non-response bias (workers with higher or lower LAN exposure being more or less likely to participate). However, small measurement numbers within strata, or not enough strata, may have limited the amount of LAN variability captured. Future studies should be conducted to assess exposures in other industries, worksites, and occupations, where exposure levels and characteristics within and between workers may differ.

Since the longest period between repeated measurements in this study was 42 days, within-worker variability in LAN exposures could increase over longer time periods (eg, due to occupational, architectural, or engineering changes). It should also be noted that only $49 \%$ of participants were repeatedly measured, with a maximum of two full-shift samples obtained per participant. Since repeated measurement rates varied across occupations $(0 \%$ for pharmacists and respiratory therapists, up to $100 \%$ for laboratory workers), these estimates may not reflect the full extent of within-worker variability for all occupations reported.

The mixed modeling methods used to assess components of variance incorporate several assumptions. It was assumed that measurements were normally distributed and independent, that within-subject variance was equal for each worker and between-subject variance was equal for all groups of workers. In this study, the distributions of LAN measurements were either approximately normal or, for lognormal distributions, were transformed prior to analyses. Independence of measurements may be assumed since participants were selected using a stratified approach with random sampling within strata, and repeat measurements were taken 11 days apart on average. Within-group and within-worker variability in LAN measurements was not perfectly equal across groups or workers, however the grouping variables accounted for most variability in all cases.

This study's assessment of photopic illuminance levels and variability allows for comparisons with most prior epidemiological studies of nighttime light exposure on health. Photopic illuminance has been used in studies of short-term alertness (35) among shift workers and in studies assessing melatonin suppression in humans (16). However, photopic illuminance measures alone cannot fully characterize circadian disruption among shift workers, since light's suppressive effect on melatonin also depends on the duration, type, and timing of exposure (23) among other factors (17). So, while the current study provides new information on shift workers' LAN exposure levels and variability using various thresholds during the typical human biological night, there are opportunities to expand upon this assessment using measures of the circadian system's sensitivity, threshold, and saturation.

The selection of an appropriate exposure metric is an important scientific consideration in exposure assessment, since observed exposure-response relationships can be sensitive to the metric chosen (7). Four LAN exposure metrics with potential relevance for epidemiological research were examined in this study; more research is needed to inform the selection of specific exposure thresholds for melatonin suppression (14) and alertness during shift work. The researcher's selection of exposure metric(s) should be based on biological considerations of exposure-response relationships for the outcome in question.

It is important to emphasize that this study did not seek to present a representative picture of LAN exposures in healthcare and emergency services workers. Rather, it sought to demonstrate that exposure levels may vary considerably across industries and occupations and that variance components should be considered in future research (for example, using a small pre-investigation of exposure variability prior to a larger epidemiological study) as a means to increase sampling efficiency, reduce measurement error, and maximize researchers' ability to detect relationships where they exist $(7,11)$.

\section{Concluding remarks}

This study represents a first step to evaluating personal LAN levels and variability in industries where shift work 
is common. The highest average levels for all exposure metrics were observed in the healthcare industry (particularly in laboratory workers and care aides) and the lowest average levels for all exposure metrics were observed in emergency services (in emergency dispatch officers); such information may be useful in targeting particular groups with low or high LAN exposure for future research. An examination of exposure variability components showed that between-group variance was large relative to withingroup variance for all exposure metrics and groupings. This suggests that high-level exposure groupings may provide a simple yet relatively effective way of characterizing individual LAN exposures in future epidemiological studies of shiftwork.

There is a need for ongoing quantitative measurement of LAN exposures and consideration of exposure variability in future studies. This is particularly important given the early stage of epidemiological research in this area and the need to clarify relationships between LAN exposures and health risks among shift workers.

\section{Acknowledgements}

The authors have no conflicts of interest to declare. ALH was supported by a Canadian Institutes for Health Research Strategic Training Fellowship (The Bridge Program), WorkSafeBC's Research Training Award program, and the University of British Columbia's Four Year Fellowship program. MK was supported in part by a Canadian Institutes for Health Research Chair in Gender, Work and Health and by the Partnership for Work, Health and Safety (a research agreement between WorkSafeBC and the University of British Columbia). The authors thank all participants for their interest and involvement in this study. The authors also thank Dr. Mariana Figueiro, Dr. Mark Rea, and Geoffrey Jones at the Rensselaer Polytechnic Institute's Lighting Research Center, for their scientific expertise and technical support regarding the Daysimeter monitors.

\section{References}

1. Cho Y, Ryu S-H, Lee BR, Kim KH, Lee E, Choi J. Effects of artificial light at night on human health: A literature review of observational and experimental studies applied to exposure assessment. Chronobiol Int. 2015;32(9):1294-310. https://doi. org/10.3109/07420528.2015.1073158.

2. International Agency for Research on Cancer. IARC Monographs on the Evaluation of Carcinogenic Risks to Humans Volume 98: Painting, Firefighting and Shiftwork. Lyon, France; 2010.
3. Vogel M, Braungardt T, Meyer W, Schneider W. The effects of shift work on physical and mental health. J Neural Transm. 2012;119(10):1121-32. https://doi.org/10.1007/s00702-0120800-4.

4. Ijaz S, Verbeek J, Seidler A, Lindbohm M-L, Ojajärvi A, Orsini $\mathrm{N}$, et al. Night-shift work and breast cancer - a systematic review and meta-analysis. Scand J Work Environ Health. 2013;39(5):431-47. https://doi.org/10.5271/sjweh.3371.

5. Stevens RG, Hansen J, Costa G, Haus E, Kauppinen T, Aronson KJ, et al. Considerations of circadian impact for defining "shift work" in cancer studies: IARC Working Group Report. Occup Environ Med. 2011;68(2):154-62. https://doi. org/10.1136/oem.2009.053512.

6. Härmä M, Kecklund G. Shift work and health - how to proceed? Scand J Work Environ Health. 2010;36(2):81-4. https://doi.org/10.5271/sjweh.2902.

7. Loomis D, Kromhout H. Exposure variability: concepts and applications in occupational epidemiology. Am J Ind Med. 2004;45(1):113-22. https://doi.org/10.1002/ajim.10324.

8. Armstrong BG. Effect of measurement error on epidemiological studies of environmental and occupational exposures. Occup Environ Med. 1998;55(10):651-6. https://doi.org/10.1136/ oem.55.10.651.

9. Loomis D, Salvan A, Kromhout H, Kriebel D. Selecting indices of occupational exposure for epidemiologic studies. Occup Hyg. 1999;5(1):73-91.

10. Kromhout H, Symanski E, Rappaport SM. A comprehensive evaluation of within- and between-worker components of occupational exposure to chemical agents. Ann Occup Hyg. 1993;37(3):253-70.

11. Nieuwenhuijsen MJ. Exposure assessment in occupational epidemiology: measuring present exposures with an example of a study of occupational asthma. Int Arch Occup Environ Health. 1997;70(5):295-308. https://doi.org/10.1007/ s004200050222.

12. Totterdell P. Work Schedules. In: Barling J, Kelloway EK, Frone MR, editors. Handbook of work stress. Thousand Oaks, California: SAGE Publications; 2005. p. 710. https://doi. org/10.4135/9781412975995.n3.

13. Stewart P, Stenzel M. Exposure Assessment in the Occupational Setting. Appl Occup Environ Hyg. 2000;15(5):435-44. https:// doi.org/10.1080/104732200301395.

14. Hunter CM, Figueiro MG. Measuring Light at Night and Melatonin Levels in Shift Workers: A Review of the Literature. Biol Res Nurs. 2017 Jul 19;19(4):365-74. https://doi. org/10.1177/1099800417714069.

15. Cajochen C, Zeitzer JM, Czeisler CA, Dijk D-J. Doseresponse relationship for light intensity and ocular and electroencephalographic correlates of human alertness. Behav Brain Res. 2000;115(1):75-83. https://doi.org/10.1016/ S0166-4328(00)00236-9.

16. Mclntyre IM, Norman TR, Burrows GD, Armstrong SM. Human melatonin suppression by light is intensity dependent. J Pineal Res. 1989;6(2):149-56. https://doi.org/10.1111/ j.1600-079X.1989.tb00412.x. 
17. Rea MS, Figueiro MG. A Working Threshold for Acute Nocturnal Melatonin Suppression from "White" Light Sources used in Architectural Applications. J Carcinog Mutagen. 2013;4(3):150-5.

18. Bierman A, Klein TR, Rea MS. The Daysimeter: a device for measuring optical radiation as a stimulus for the human circadian system. Meas Sci Technol. 2005;16(11):2292-9. https://doi.org/10.1088/0957-0233/16/11/023.

19. Figueiro MG, Hamner R, Bierman A, Rea MS Comparisons of three practical field devices used to measure personal light exposures and activity levels. Light Res Technol. 2012;45(4):421-34. https://doi. org/10.1177/1477153512450453.

20. Miller D, Bierman A, Figueiro M, Schernhammer E, Rea M. Ecological measurements of light exposure, activity, and circadian disruption. Light Res Technol. 2010;42(3):271-84. https://doi.org/10.1177/1477153510367977.

21. Rea MS, Brons JA, Figueiro MG. Measurements of light at night (LAN) for a sample of female school teachers. Chronobiol Int. 2011;28(8):673-80. https://doi.org/10.3109/ 07420528.2011.602198.

22. Young CR, Jones GE, Figueiro MG, Soutière SE, Keller MW, Richardson AM, et al. At-sea trial of 24-h-based submarine watchstanding schedules with high and low correlated color temperature light sources. J Biol Rhythms. 2015;30(2):14454. https://doi.org/10.1177/0748730415575432.

23. Rea MS, Figueiro MG, Bierman A, Bullough JD. Circadian light. J Circadian Rhythms. 2010;8(1):2-11. https://doi. org/10.1186/1740-3391-8-2.

24. DiLaura, David; Houser, Kevin; Mistrick, Richard; Steff G, editor. The Lighting Handbook 10th Edition. New York, USA: The Illuminating Engineering Society; 2011.

25. Papantoniou K, Pozo OJ, Espinosa A, Marcos J, Castao-Vinyals G, Basaga-a X, et al. Circadian variation of melatonin, light exposure, and diurnal preference in day and night shift workers of both sexes. Cancer Epidemiol Biomarkers Prev. 2014;23(7):1176-86. https://doi.org/10.1158/1055-9965.EPI-13-1271.

26. Grundy A, Tranmer J, Richardson H, Graham CH, Aronson KJ. The influence of light at night exposure on melatonin levels among Canadian rotating shift nurses. Cancer Epidemiol Biomarkers Prev. 2011;20(11):2404-12. https:// doi.org/10.1158/1055-9965.EPI-11-0427.
27. van Tongeren MJA, Kromhout H, Gardiner K, Calvert IA, Harrington JM. Assessment of the sensitivity of the relation between current exposure to carbon black and lung function parameters when using different grouping schemes. Am J Ind Med. 1999;36(5):548-56. https://doi. org/10.1002/(SICI)1097-0274(199911)36:5<548::AIDAJIM7>3.0.CO;2-V.

28. Kromhout H, Loomis DP, Mihlan GJ, Peipins LA, Kleckner $\mathrm{RC}$, Iriye R, et al. Assessment and grouping of occupational magnetic field exposure in five electric utility companies. Scand J Work Environ Health. 1995;21(1):43-50. https://doi. org/10.5271/sjweh.7.

29. Symanski E, Sällsten G, Barregård L. Variability in airborne and biological measures of exposure to mercury in the chloralkali industry: implications for epidemiologic studies. Environ Health Perspect. 2000;108(6):569-73. https://doi. org/10.1289/ehp.00108569.

30. Symanski E, Maberti S, Chan W. A meta-analytic approach for characterizing the within-worker and between-worker sources of variation in occupational exposure. Ann Occup Hyg. 2006;50(4):343-57.

31. Tielemans E, Kupper LL, Kromhout H, Heederick D, Houba R. Individual-based and group-based occupational exposure assessment: Some equations to evaluate different strategies. Ann Occup Hyg. 1998;42(2):115-9. https://doi.org/10.1016/ S0003-4878(97)00051-3.

32. Fernandez RC, Peters S, Carey RN, Davies MJ, Fritschi L. Assessment of exposure to shiftwork mechanisms in the general population: the development of a new job-exposure matrix. Occup Environ Med. 2014;71(10):723-9. https://doi. org/10.1136/oemed-2014-102101.

33. Goldberg M, Kromhout H, Guenel P, Fletcher AC, Gerin M, Glass DC, et al. Job Exposure Matrices in Industry. Int J Epidemiol. 1993;22(Supplement 2):S10-5. https://doi. org/10.1093/ije/22.Supplement_2.S10.

34. Jewett ME, Rimmer DW, Duffy JF, Klerman EB, Kronauer RE, Czeisler CA. Human circadian pacemaker is sensitive to light throughout subjective day without evidence of transients. Am J Physiol - Regul Integr Comp Physiol. 1997;273(5):R1800-9.

35. Cajochen C. Alerting effects of light. Sleep Med Rev. 2007;11(6):453-64. https://doi.org/10.1016/j. smrv.2007.07.009.

Received for publication: 9 May 2017 